\title{
Minimizing Resistance to Change: The Role of Communication and Perceived Organizational Justice
}

\author{
Ayu Aprilianti Lizar ${ }^{1}$, Febri Nila Chrisanty ${ }^{2}$, Putu Ayu Novita ${ }^{3}$, Silvia Susanti Dewi Teguh Endaryono ${ }^{4}$ \\ Faculty of Business and Economics, Universitas Indonesia, Depok, West Java, Indonesia 1,2,3,4 \\ 1ªyuaprilianti@gmail.com
}

\begin{abstract}
This study aims to analyze the effect of change communication on worker's resistance to change mediated by perceived organizational justice, in a manufacturing company in Indonesia. This company has been undergoing organizational change for the past two years. Data from 260 respondents were collected using survey method and then analyzed with Structural Equation Modeling (SEM). The result showed that change communication has negative and significant effect on resistance to change and positive and significant effect on perceived organizational justice. Moreover, perceived organizational justice has negative and significant effect on resistance to change, and the effect of communication on resistance to change is partially mediated by perceived organizational justice. This research corroborates the previous research that states change communication and organizational justice play an important role in minimizing resistance to change.
\end{abstract}

Keywords: Resistance to Change, Communication, Perceive Organizational Justice, Organizational Change

\section{Introduction}

In today's 4.0 industrial era, organization is often challenge with the necessity to implement a new system and technology in which at the end change the way business process was done. This necessity is driven by the pressure to become more efficient, agile, and also competitive. As the consequences, organization needs to conduct series of organizational change processes effectively, in order to improve its business processes and finally increase the organizational performance. In addition to that, the change is one of the most critical aspects in creating more effective management. [1] Organization which does not have the capability to change, will be decline gradually and finally peril from the market.[2]

Organizational change process is not an easy thing to do. It needs commitment from the toplevel management, and also full support from all the organization members. It is not rare that the organizational change process fails. Some of the main causes for failure in organizational change include lack of top level management support, unclear vision, mission and tactical plan, technological difficulties in supporting the change, lack of financial resources and the most crucial is unable to resolve problems related to human resources or individuals in the organization [3]; [4] 
Among the problems causing the failure of change in the organization, individuals or workers are often referred to as the most influential one. This statement is highlighted by Madsen, John, and Miller [5] who proposed that organizational change interventions will not be succeed unless the individuals within the organization also change.

Oreg [6] stated that each individual shows a different response to change. There are some individuals who will give a positive response toward the change process, while others show the opposite. In other words, there are two possible individual attitudes in dealing with changes in the organization. Moreover, the individual can accept the change process that occur in the organization or reject it and becoming resistance to change.

Saruhan [7]states that the most common obstacle to successful organizational change is the resistance of worker in the organization. Resistance to change is a negative emotional or behavioral response to changes in work routines which is real or imaginative [4].

There are several aspects or factors which can cause individuals in an organization accept or resistant to change. If the change leader cannot comprehend the situation, manage employee resistance and then alter it into commitment, the organizational change process will be at risk. This condition calls numerous researchers to investigates factors that can cause individuals resistance to change.

Hussey [1]stated that one of the factors which can minimize resistance to chance is communication, while Raina [8] stated that communication is a process which plays a central role in determining organizational success or failure. These statements were also supported by Klonek, Kauffeld and Lehmann-Wilenbrock [9]who stated that an effective change communication plays an important role in organizational change process. Effective communication can help individuals to understand the logic of the change process that includes what, why, when, who, how, and also what's in it for me.

In addition to communication, previous resource also found that there are other factors which can affect individual resistance to change. One of the factors is perceived organizational justice. Krause [10] stated that perceived organizational justice is one of the factors that can affect workers' readiness as well as resistance to change. Cobb, Folger, and Wooten [11] found that a positive perception of organizational justice during the process of change will lead to organizational commitment, trust, and willingness to accept the change.

Organizational justice is the overall perception of what is fair in the organization. Organizational justice is divided into three dimensions; distributive, procedural and interactional justice. Distributive justice relates to employee's perception about the fairness in the process of resolving dispute and allocating resources. Procedural justice is defined as the fairness in the process that leads to outcomes, while interactional justice refers to the treatment that an individual receives as decisions are made and delivering the news with sensitivity and respect [2]; [12]

Individual react to actions and decisions made by organizations/management day bay day. An individual's perception whether these decisions as fair or unfair can influence the individual's subsequent attitudes and behaviors. Jones and Martens [5]stated that that there will be a strong desire to change within the employees if the employee feels justice in the organization.

This study aims to investigate the role of effective change communication and perceived organizational justice in minimizing resistance to change. Additionally, this study also aims to investigate the role of organizational justice as the mediator in the relationship between change communication and resistance to change in Indonesia context. Previous research about organizational change, specifically resistance to change, mostly conducted in western culture which according to Hofstede adopt more individualistic as well as low power distance value. On the contrary, Indonesian people, as most of Asian country in majority adopt more collectivist as 
well as high power distance values. This value difference raised questions whether the research model is also applicable in Indonesian context.

This study was conducted in a manufacturing company located in Jakarta and West Java, Indonesia, which are undergoing organizational change. Due to fierce competition and technological advancement, this company needs to implement new IT system and adopt new technology in production to increase performance.

Three research questions which are going to be answered through this research are:

1) Does change communication have positive significant effect on workers' resistance to change?

2) Does change communication have positive and significant effect on perceive organizational justice?

3) Does perceived organizational justice have positive and significant effect on worker's res]'stance to change?

4) Does perceived organizational justice mediates the relationship between change communication and workers' resistance to change

\section{Literature Review}

Change can be defined as doing things in a new way as a result of technological advancement, invention of a new systems, following new management procedures, or reorganizing [13]; [14]state that the individual's resistance to change is one of the causes of organizational change failure. Moreover, Palmer, Dunford \& Akin [13]described two types of change resistance; active and passive.

The active resistance to change is characterized by frequent organizational members criticizing, making mistakes, mocking, feeling afraid, using facts selectively, blaming, damaging, frightening/ threatening, changing facts, obstructing, initiating rumors and opposing the change process, change leader, change goals in particular as well as organization. Meanwhile, the passive resistance to change is characterized by agreeing verbally but not following the changes, failing to implement the changes, procrastinating in doing something, ignoring, hiding (information, advice, help, support) and following changes which lead to failure.

Palmer, Dunford,\& Akin [15]also states that more than one factor can lead to resistance to change. Some of the factors are individual dispositional characteristic, there are some people who do not like change, feel uncomfortable with uncertainty, have negative perceptions on the consequences of change, want to maintain the old culture, power conflict, lack of confidence in one's own ability to change, the belief that changes are not in line with the members of the organization, and members of the organization do not agree with the way changes are made.

Kreitner and Kinicki [4] describe resistance to change as an emotional response or negative behavior towards changes in work routines which is real or imaginative. While Oreg [6]states that resistance to change refers to the tendency of individuals to prevent change with actions that show how he/her rejects the change. He also added that change will affect every aspect of an individual's life. However, the response of each individual will be different, some of them will accept the change process and actively participate to help the change succeed, while other will avoid or event reject the changes. [16] According to Oreg [6] resistance to change consists of four dimensions, which are; (a) routine seeking behavior, in which organizational change is seen as routine disruption or opportunity to increase stimulation. When an individual faces a new stimulation, such a thing that may be not in line with their situation which leads to stress. (b) emotional reaction which is the amount of individual's stress and worries in facing changes. For example, when an organizational member considers a change decrease their control on their own life, 
therefore the individual will be stressed and tend to reject the changes. (c) short term focus, in which in term of the initial change aspect mostly involves more duties and energy instead of maintaining the status quo, therefore some workers will reject the changes [5]), even though each individual has the probability to support certain changes, and lastly (d) cognitive rigidity, some researchers have studied the cognitive process which is the basis of someone to give response on an organizational change. Such thing determines how a worker process information about changes and determine how they should react. A stiff and close-minded worker tend to less willing and less capable in adapting to the new situation.

Communication is a process in which information is transmitted and understood between two or more people [16] Communication aims to control, motivate, deliver expressions as well as emotions, and provide information [2]; [8]states that communication is a process which plays a central role in determining which organization will be succeed or fail. Postmes, Tanis, \&De Wit [17] state that there are two types of communication, based on the direction. They are vertical and horizontal communication. vertical communication helps the management define an organization, and thus it can strengthen the definition of the workers' existence in the organization. Vertical communication is divided into two directions which are downward communication and upward communication. Downward vertical communication is communication which flows from one level of a group to the lower level. Furthermore, the second type which is upward vertical communication is a communication which flows from the lower level to the higher or upper level.

In addition to vertical communication, [7]states that horizontal communication occurs between members of the same group. Horizontal communication is a message conveyed between individuals in the same organizational level [18]Horizontal communication in an organization occurs during the staff meetings, information presentation and shift turnover [19]

Organizational justice reflects how each individual feels that they are treated fairly in the workplace [4]; Additionally, [20]mentions that organizational justice focus on the impact of managerial decision making, perceived quality, the effect of justice, the relationship between individual and situational factors and explains perceptions of individual justice in the organization. The perception of organizational justice has four dimensions; distributive justice, procedural justice, and interactional justice. Interactional justice is divided into two; informational justice and interpersonal justice [20]

\section{Research Model}

This study's research model replicate the model developed by Saruhan [7] The research model illustrates how organizational justices mediates the effect of communication on workers' resistance to change. This model was developed base on the model of change recipient reaction to organizational change that was developed by dynamic of resistance to change framework which was developed by Oreg, Vakolla and Armenakis [21] That model suggests that communication and organizational justices are the two variables on the process aspects of change that have important role in affecting resistance to change. 


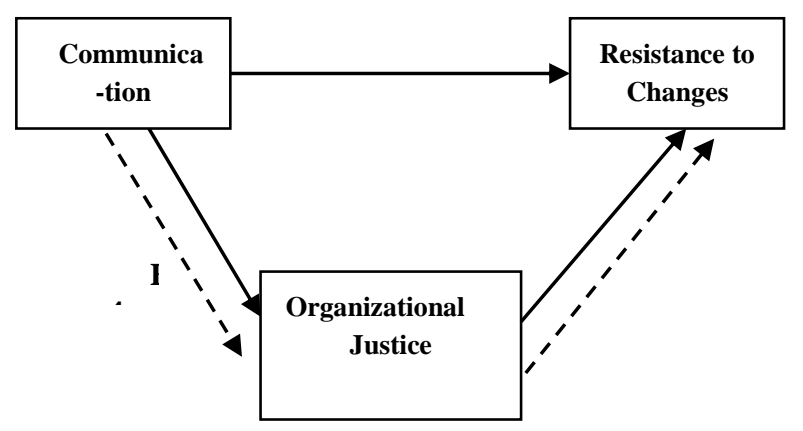

Fig. 1. Research Model [7]

\section{Research Hypothesis}

Bovee [7], Thill and Schatzman [22] stated that cooperation and interpersonal relationship occur more easily with good communication and appropriate social interaction. Furthermore, this can help organization to reduce anxiety and uncertainty felt by the workers about the results of the change implementation. McShane and VonGlinow [16]also stated that the existence of honest communication which frequently happens is the first priority and strategy needed in organizational change. In addition, several studies have shown a positive relationship between employee communication and support for change efforts [7]. Thus, based on the explanation above, we develop hypothesis 1 as follow:

\section{H1: Communication negatively affects the resistance on changes.}

Saruhan [7]states that to yield a successful change effort, communication should also be conducted to improve workers' perceptions of justice in the organization. Some empirical studies also emphasize the importance of communication in the perception of justice. This is aligned with Kilbourne et al. [23] who stated that the amount of information provided by an organization to its worker will affect the employees' perceptions of organizational justice. Based on this, the hypothesis we developed hypothesis 2 which is:

H2: Communication positively affects the perception of organizational justice.

Jones and Martens [5]stated that there will be a strong desire to change in an individual if the individual gets organizational justice. Employees who perceive the existence of organizational justice tend to be better in dealing the changes [24]; [24]also mention that the existence of a positive perception of organizational justice during the change process will lead to organizational commitment, trust, and willingness to accept change. Accordingly, we proposed hypothesis 3 which is:

H3: Perception of organizational justice negatively affects the resistance to changes.

Daly and Geyer [25]found that the positive effect of communication on workers' resistance to change is mediated by perceptions of justice. In addition, providing accurate information during the change process with the perception of justice will reduce the resistance to change [26]It can be concluded that the existence of accurate communication from the organization to it's workers will 
improve workers' perception of organizational justice which finally decrease workers' resistance to change. Accordingly, we develop the fourth hypothesis which is:

H4: The effect of communication on resistance of change will be mediated by perception of organizational justice.

\section{Research Method}

Thisstudy follows conclusive research procedure with descriptive cross-sectional single type. Descriptive research is a type of conclusive research which has the main purpose of describing something. Single cross-sectional is a study where a sample of respondents is taken from the target population in which the information is also obtained once only [27]. In general, we want to investigate the effect of communication onresistance to change and organizational justice, and the effect of organizational justice on resistance to change, and lastly, we also want to investigate whether perception of organizational justice mediates the relationship between communication and resistance to change.

The sampling method used in this study is non-probability sampling with a type of purposive sampling. Malhotra [27]states that non-probability sampling is subjective sample selection in which researchers have personal judgment or sampling techniques that do not use the opportunity procedure to choose, but are chosen based on the judgment of the researcher. Purposive sampling according to Malhotra [27]is that respondents taken by researchers become samples because researchers consider the sample to have information needed for the research. In this study, researchers will only take samples of respondents with characteristics of working for at least one year

The population of this study are the workers of Company ABC. The workforce consists of as many as 365 people. Based on the calculation of the Slovin formula, it was found that the minimum number of samples in this study were 230 workers. The questionnaires distributed by the researchers were 290 sheets, and 260 were returned and can be processed for further analysis.

In this study, the measurement used Likert 1-6 scale, which contains statements for resistance to change from Oreg [6]Organizational justice from Colquitt; [20]and change communication from Postmes, Tanis, \& De Wit [17]. Before conducting the field test, a pre-test was conducted to 30 respondents first which was processed using SPSS. The data collected in this study were processed and analyzed using Structural Equation Modeling (SEM).

\section{Research Result}

The pre-test result of this study indicates that all indicators of the research variables are valid and reliable. All indicators have KMO values, factor loading, and Cronbach alpha above the standard, of which the KMO and the loading factor are above 0.5 and the Cronbach alpha is at least 0.6 .

After conducting the validity and reliability test on the measurement model using SEM, it was found that all indicators are valid and reliable. The validity test of the measurement model was done by looking at the $\mathrm{t}$-value from the standardized loading factor of each observed variable in the model. The t-value must have a value of more than 1.64. In the analysis of the measurement model, in addition to looking at the $\mathrm{t}$-value, the standardized loading factor or SLF value was also seen, where the SLF value must reach a value of 00.50 and if it can reach a value of $\geq 0.70$, it will be more ideal (Hair, Black, Babin, Anderson, \& Tatham, [28]). The analysis of the measurement model show that the RMSEA value from this research model is 0.076 which can be considered as good fit. A model can be considered as good fit if it has RMSEA value below 0.08 . 
After analyzing the measurement model, the next step is to analyze the structural model. In the analysis of the structural model, we found RMSEA value of 0.058 which is considered as good fit. The figure 2 will shows the structural model result.

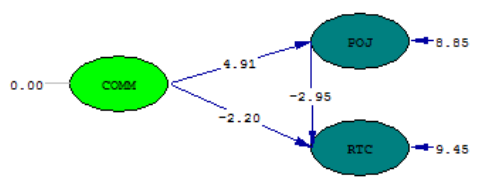

Fig. 2. Path Diagram of the Overall Model

In a one-tailed test, the relationship between positive latent variables that has the $t$-value $\geq 1.645$ shows that the relationship between the latent variables is significant, so the hypothesis

Table 1. $t$-value significance test result

\begin{tabular}{|l|l|l|l|}
\hline No. & Path & t-value & Conclusion \\
\hline 1 & $\begin{array}{l}\text { Communication } \rightarrow \\
\text { Resistance to } \\
\text { Change }\end{array}$ & -2.20 & Significant \\
\hline & $\begin{array}{l}\text { Communication } \rightarrow \\
\text { Perception of } \\
\text { Organizational } \\
\text { Justice }\end{array}$ & 4.91 & Significant \\
\hline & $\begin{array}{l}\text { Perception of } \\
\text { Organizational } \\
\text { Justice } \rightarrow \\
\text { Resistance to } \\
\text { Change }\end{array}$ & -2.95 & Significant \\
\hline
\end{tabular}

is accepted. Meanwhile, if the relationship between the latent variables is negative, then the relationship between the latent variables can be significant and the hypothesis can be accepted if the $\mathrm{t}$-value is $\leq-1.645$. If the condition is not fulfilled, it indicates that there is no significant effect on the other latent variables. Based on the picture 2, we can see the effect between communication, perception of organizational justice and resistance to change which will be shown in the following table.

Based on table 1 above, it can be concluded that the relationships between the latent variables in this study is significant. Besides looking at the t-value to determine the significance, the attribute of $\mathrm{t}$-value (positive or negative) also determined the direction of the relationship between one latent variable to another. If the relationship between latent variables is positive; $t$-value $\geq$ 1.645; then the relationship will be positive. Conversely, if the relationship between latent variables is negative; $t$-value is $\leq-1.645$; then the relationship will be negative. If the two conditions are not met, then the relationship hypothesis will be rejected.

\section{H1: Communication negatively affects the resistance to change.}

From the hypothesis test result, it was found that the hypothesis 1 obtained a t-value of -2.20 which means that $\mathrm{H} 1$ is accepted since the $\mathrm{t}$-value $\leq-1.645$. This result indicates that the 
communication variable has a negative and significant effect on workers' resistance to change. From the result obtained, it can be interpreted that the higher the change communication score was in the organization, the lower the workers' resistance to change will be. Conversely, the lower the communication score was as perceived by the worker, will increase workers' resistance to change. This finding is in line with the previous research conducted by Saruhan [7]that also found negative and significant effect of communication on resistance to change.

\section{H2: Communication positively affects the perception of organizational justice.}

The result of this study found the t-value 4.91 which means that $\mathrm{H} 2$ is accepted. It indicates that communication variable has a positive and significant effect on the perception of organizational justice. From the result obtained, it can be interpreted that the higher the communication score was as perceived by the workers, the higher workers' perception of organizational justice will be. Conversely, if the communication score is lower (perceived as in effective), the perception of organizational justice will be worsening as well. This finding also in line with the previous research conducted by Saruhan [7]

\section{H3: Perception of organizational justice negatively affects the resistance to change.}

The result of his study found also t-value of -2.95 for H3.Thus, H3 is accepted, because the t-value is $\leq-1.645$. This result indicates that workers' perception of organizational justice have negative and significant effect on resistance to change. It can be interpreted that the higher worker perception on organizational justice, will decrease resistance to organizational change. Conversely, if the perception of organizational justice as perceived by the worker is higher, then the resistance to change will be increase. This finding also in line with the previous research finding conducted by Saruhan [7]He found that there was a negative and significant effect of perception of organizational justice on workers' resistance to change.

H4: The effect of communication on the resistance to change is mediated by the perception of organizational justice.

This result found that the t-value of relationship between communication and perception of organizational justice was 4.91 , which means the relationship between communication and perception of organizational justice is significant because the $t$-value is $\geq 1.645$. Therefore, the relationship of perception of organizational justice to the resistance of change is also significant, in which the t-value obtained was $-2.95 \leq-1.645$. A significant relationship of communication on resistance to change through perception of organizational justice is a mediating or indirect effect relationship. The indirect effect between the two variables occur when there is no direct arrow between the two latent variables, but through one or more other latent variables according to the existing path [20]. Thus, it can be concluded that hypothesis 4 is accepted because there is a mediation or indirect effect of the communication variable on the resistance to change variable through the perception of organizational justice variable.

\section{Discussion}

Based on the conclusions, it is proven that change communication has negative and significant effect on workers' resistance to change. In the results of this study, we found that the respondents (workers of Company $\mathrm{ABC}$ ) perceived change communication as relatively high during the 
organizational change process. We also found that that vertical communication has lower mean than horizontal communication.

Vertical communication occurs between different hierarchical level as form the managers to subordinates. From the descriptive result we can see that the lowest mean score from vertical communication is from the aspect of providing information about the organizational change. Lack of information regarding matters related to organizational change can cause uncertainty among the worker. This condition can lead to the tendency of employees to resist the ongoing organizational changes. In order to overcome this, the change agents are required to be more proactive in providing information regarding the organizational changes to all employees. The information provided can be carried out by conducting more socialization, giving pocket books containing of all information on the change process, and also conducting regular meetings to discuss the change that can provide two ways communication.

Based on this study, it is also proven that the perception of organizational justice has a negative and significant effect on resistance to change. Overall, from the descriptive analysis it was found that the perception of organizational justice in the Company $\mathrm{ABC}$ shows that justice was implemented during the change process and it was perceived as good. The type of justice of the organization that has the lowest value in this study is related to distributive justice. Distributive justice is related to the way the organization distribute resources or rewards to the workers. Distributive justice which are need to be improved in this study are related to salaries, rewards, evaluations, and promotions received by the employees which are perceived as not reflecting the contributions given by the employees. This finding is very important to be considered by the organization, since the perception of organizational justice significantly influential the sustainability of the organizational change process.

Descriptive statistic of this research showed that the level of resistance to change at Company $\mathrm{ABC}$ is quite high. The resistance to change is one of the obstacles in the process of organizational change. In this study, there are four types of dimensions of resistance to change, which is routine seeking that include the extent to which one enjoys and seeks a stable and routine environment. Then, related to emotional reaction including some emotional reactions to changes that can cause resistance to change. Next is the short-term focus including covering the extent to which individuals feel uncomfortable with change in the short term compared to the benefits of change in the long run. Finally, cognitive rigidity is an individual's reluctance to consider alternative ideas and perspectives from change.

In this study, the highest mean value is shown on the dimension of short-term focus, this means that when there is someone or some party who presses a worker to change something, they tend to reject the change even though the employee thinks that the change can ultimately benefit the employee, because they focused attention more on short term result rather than long term.

On routine seeking dimension, the result shows that workers prefer routines compared to unexpected events in everyday life and show that employees prefer to do the same things rather than trying new and different things. This indicates that workers tend not to accept changes and things that are new. This indicates the tendency of employees within the Company ABC. This problem needs to be taken seriously to prevent it from hampering the organizational change process in company $\mathrm{ABC}$.

There are two strategies that can be implemented to overcome the problem of resistance to change. The change management team, should recognize the characteristics of employees better, so they can understand what are the needs and desires of employees related to the process of organizational change. The relationship between change agent and employee must also be well established, so that if there are things to be conveyed from both parties, they can be conveyed well through the right means. 
In addition, as explained earlier, communication and perception of organizational justice are important in affecting the resistance to change. Accordingly, communication especially the one that regarding organizational change should be design carefully. Involving the employees in the decision-making during organizational change process is also an important thing that needs to be done by the organization. It should be done so that the employees can feel directly involved in the process of change. In addition, the full involvement of employees in the process of change will makes the employees do not feel threatened by the changes itself.

Based on the results of this study as a whole, it was found that resistance to change at company $\mathrm{ABC}$ is significantly affected by communication and perception of organizational justice. Because of this result, organization needs to consider and pay more attention to these factors to minimize the resistance level of change in the organizational change process conducted at Company ABC.

\section{Conclusion}

Communication has a negative and significant effect on resistance to change. Communication has a positive and significant effect on the perception of organizational justice. Perception of organizational justice has a negative and significant effect on resistance to change. The effect of communication on the resistance to change is mediated partially by the perception of organizational justice.

\section{Research Limitation}

The following are some limitation of this research:

1. In this study, the sample was taken using convenient sample. The researcher did not have the ability to distribute the questionnaire independently choose the sample. We asked the help from HR department to distribute taken does not cover all units in the organization. Therefore, this study has limitation in term of generalizability. In further research, it is suggested to use other sampling method that can increase the generalizability of the research.

2. This study only covered one organization. Again, this condition limits the generalizability of this result. In future research it is suggested to conduct research from more that one company.

3. The questionnaire used in this research was self-report. This type of questionnaire is prone to bias.

4. This research only involved two variables, and there are other variables that can also influence resistance to change. For future research it is suggested to add other variables such as leadership, organizational trust, employee involvement, employee empowerment, organizational culture, and others.

\section{REFERENCES}

[1] D. E. Hussey, How to Manage Organisational Change. London: Kogan Page Limited, 2000.

[2] S. P. Robbins and Judge, Organizational Behavior, 11th ed. New York: John Wiley and Sons, 2007.

[3] R. D. Foster, Individual resistance, organizational justice and employee commitment to planned organizational change. Unpublished doctoral dissertation. The University of Minnesota, 2008.

[4] R. Kreitner and A. Kinicki, Organizational behavior, 9th ed. New York: McGraw-Hill, 2011. 
[5] D. A. Jones and M. L. Martens, "The mediating role of overall fairness and the moderating role of trust certainty injustice-criteria relationships: the formation and use of fairness heuristics in the workplace," Journal of Organizational ,Behavior, vol. 30, no. 8, pp. 1025$1051,2009$.

[6] S. Oreg, "Resistance to change: developing an individual differences measure," Journal of applied Psychology, vol. 88, no. 4, p. 680, 2003.

[7] N. Saruhan, "The role of corporate communication and perception of justice during organizational change process," Business and Economics Research Journal, vol. 5, no. 4, pp. 143-166, 2014.

[8] R. Raina, Timely, Continuous \& Credible Communication \& Perceived Organizational Effectiveness. Indian Journal of Industrial Relations, pp. 345-359, 2010.

[9] W. E. K. Lehman, J. M. Greener, and D. D. Simpon, "Jorunal of Substance A buse," Treatment, vol. 22, pp. 197-2, 2002.

[10] T. R. Krause, “Assessing readiness for change," Occupational, vol. 70, no. 3, pp. 24-26, 2008.

[11] A. T. Cobb, R. Folger, and K. Wooten, "The role justice plays in organizational change," Public Administration Quarterly, pp. 135-151, 1995.

[12] J. A. (200. Colquilt, "On the Dimensionality of Organizational Justice: a Construct Validation of a Measure," Journal of Applied Psychology. 86, vol. 3, pp. 386-400.

[13] B. Palmer, Change management: Overcoming resistance to change.Quality, vol. 37. progress, 2004.

[14] Y. Chauhan and S. Kumar, Does founder ownership affect foreign investments? 2017.

[15] K. Cafferkey and T. Dundon, "Explaining the black box: HPWS and organizational climate," Personal Review, vol. 44, pp. 666-668, 2015.

[16] S. L. McShane, V. Glinow, and M. Ann, Organizational Behavior, 4th ed. New York: McGraw-Hill Companies, Inc, 2009.

[17] T. Postmes, M. Tanis, and Bd. Wit, Eds., "Communication and Commitment in Organization: A Social Identity Approach. Group processes and Intergroup,” Relations, vol. 4, no. 3, pp. 227-246, 2001.

[18] P. H. Andrews and R. T. Herschel, Organizational Communication Empowerment in a Technological Society. Houghton Mifflin Company, 1996.

[19] J. E. Spillan, M. Mino, and M. S. Rowles, "Sharing Organizational Messages through Effective Lateral Communication," Communication Quarterly, vol. 50, no. 2, pp. 96-104, 2002.

[20] J. A. Colquitt and J. C. Shaw, "How should Organizational Justice be Measured?," in Handbook of Organizational Justice, Jg. J. A. Colquitt, Ed. Mahwah, NJ: Lawrence Erlbaum, 2005, pp. 113-152.

[21] A. A. Armenakis, S. G. Harris, and MossholderKW, "Creating readiness for organizational change," Human Relation, vol. 46, no. 6, pp. 681-703, 1993.

[22] C. L. Bovee, J. V. Thill, and E. B. Schatzman, Business Communication Today. Delhi:Pearson Education, 2003.

[23] L. M. Kilbourne, A. M. O’Leary-Kelly, and S. D. Williams, "Employee perceptions of fairness when human resource systems change: The case of employee layoffs," in Research in organizational change and development, 9, 1996, pp. 25-48. 
[24] M. A. Konovsky and R. Folger, "The Effects of Procedures, Social Accounts and Benefits Level on Victims'," Layoff Reactions. Journal of Applied Social Psychology, vol. 21, pp. 630-650, 1991.

[25] J. P. da. P. D. G. Daly, "The Role of Fairness in Implementing Large-scale Change: Employee Evaluation of Process and Outcomes in Seven Facility Relocation," Journal of Organizational Behavior, vol. 15, pp. 623-638, 1994.

[26] A. Chawla, "Organizational Change Initiatives as Predictors of Resistance to Change. Unpublished Doctoral Deissertation. The University of Guelph," Change. Journal of Business and Management, vol. 12, no. 2, p. 93, 1999.

[27] N. K. Malhotra, Marketing Research : An Applied Orientation, 6th Ed. New Jersey: Pearson Education, Inc, 2010.

[28] R. C. Anderson, S. A. Mansi, and D. M. Reeb, "Board characteristics, accounting report integrity, and the cost of debt," Journal of Accounting and Economics, vol. 37, no. 3, pp. 315-342, 2004. 